\title{
A literariedade do discurso platônico: uma análise cenográfica da República I (327a a 331d)
}

\section{The literariness of the platonic discourse: a scenographic analysis of the Republic I (327a to 331d)}

\author{
Felipe Vale da Silva ${ }^{1}$ \\ Sabrine Ferreira da Costa ${ }^{2}$
}

DOI: $10.28998 / 2317-9945.2020 \mathrm{n} 65 \mathrm{p} 41-47$

\begin{abstract}
Resumo
O artigo analisa a cena de abertura de A República, de Platão, a partir de ferramentas dos estudos literários e da historiografia, levando em conta contribuições recentes da crítica platônica anglo-germânica. Se, por um lado, persiste a ideia de que na República se encontra um manifesto contra a ficção literária encarada como um registro potencialmente falsificador da realidade —, há de se considerar, por outro, quão artisticamente elaborado o diálogo socrático é. Argumentamos que o próprio formato dialógico do texto impede uma interpretação de Platão como um racionalista dogmático, cético ante o potencial da poesia. Ao contrário, o jogo entre expectativas genéricas, ao qual somos expostos desde os embates iniciais entre as personagens Sócrates, Glauco, Trasímaco e Céfalo - em trechos que vacilam entre o registro dramático e a filosofia -, exige tanto uma reapreciação dos posicionamentos platônicos perante as belas artes quanto uma reconsideração do peso de cenários, personagens e tempos narrativos como elementos constituintes da argumentação filosófica.
\end{abstract}

Palavras-chave: Platão. A República (Politeia). Sócrates (personagem). Mimese

\begin{abstract}
The article aims to analyze the opening scene of Plato's Republic based on literary studies and bistoriography devices, taking into account recent contributions from Anglo-Germanic Platonic studies. If, on the one hand, the idea that in the Republic one may find a manifesto against literary fiction — taken as a potentially falsified version of reality - still persists, one has also to consider, on the other hand, how artistically elaborated is the Socratic dialogue. We will argue that the dialogical format of the text itself precludes an interpretation of Plato as a dogmatic rationalist, skeptical towards the potential of poetry in general. Rather, the play between generic expectations and what one already finds in the opening discussions among the characters Socrates, Glaucus, Thrasymachus and Cephalus - in scenes that waver between the dramatic format and philosophy - require not only a re-examination of Plato's claims on the arts, but also of the value of scenarios, characters and narrative temporality as constituent elements of philosophical argumentation.
\end{abstract}

Keywords: Plato. The Republic (Politeia). Socrates (character). Mimesis

Recebido em: 25/10/2019.

Aceito em: 25/12/2019.

\footnotetext{
${ }^{1}$ Doutor em Letras Português/Alemão pela Universidade de São Paulo. Desenvolveu pesquisa de pósdoutorado na Universidade Federal de Goiás.

${ }^{2}$ Graduada em Letras Francês pela Universidade de São Paulo.
} 
Introdução

"A República é uma obra poética não menos mimética do que a Ilíada e a Odisseia" segundo Stanley Rosen na introdução de seu livro Plato's Republic: a study (2005, p. 3) ${ }^{3}$. A afirmação pode soar um contrassenso se recorrermos aos próprios argumentos presentes na obra platônica a respeito da poesia: há uma inferência de que os charmes da arte da palavra, que age sob propósitos da persuasão, oferecem um perigo à autoridade política do filósofo (como consta em 377e) ${ }^{4}$. A poesia seria, ao menos potencialmente, um registro proliferador de falsificações da realidade. Ela cria um público que se mostra apto aos fascínios da imaginação, mas alheio aos rigores da razão. A retórica buscada por Sócrates, por sua vez, se contrapõe a tal formato de discurso e se propõe como uma retórica da verdade.

Há, porém, uma construção sutil de cenários, personagens e situações que nos permite desenvolver uma interpretação da República como um diálogo filosófico de moldes literários. A República é dotada, portanto, de literariedade, conceito entendido aqui como uma rede de propriedades oriundas da tradição literária que, por vezes, se mesclam a demais registros textuais. Nosso ponto de partida é entender o pano de fundo, digamos, construído por Platão no início do texto — de 327a a 331d — pensando em que medida as personagens elencadas e deslocamentos por espaços amplificam significados presentes nos diálogos em si. É como se Platão preparasse seus leitores históricos, já do início, para determinado registro criativo antes de iniciar sua argumentação filosófica propriamente dita.

O texto inicia com a declaração da personagem-narrador Sócrates: "Desci ontem ao Pireu" (327a). O diálogo se desenvolve, portanto, no Pireu, porto contíguo à cidade de Atenas, a quilômetros do centro urbanizado. E, se quisermos expandir a imagem, a quilômetros da ágora, o centro pulsante da vida democrática ateniense. Mais de um intérprete sugeriu analogias da cena com a $\varkappa \alpha \tau \dot{\alpha} \beta \alpha \sigma \iota \varsigma$ de narrativas épicas; é como se Sócrates, figura que já transitava na ágora ateniense nos diálogos de juventude de Platão, declarasse estar adentrando um universo distinto, onde as coisas ocorrem de forma diferente $^{5}$. A continuação da descrição mostra o Pireu como cenário para a estreia do festival de Bendis, uma deusa oriunda da Trácia, recém-incorporada ao panteão de deidades atenienses (JANOUCHOVÁ, 2013, p. 95; ver descrição em 354a). Se não é uma região de instabilidade - como se figurasse na obra como uma contra-imagem de Atenas -, o Pireu, ao menos, aparece como um local marcado por ecletismo, pela presença de valores culturais e práticas estrangeiras. Simultaneamente, um tal caráter não-grego implica certa desordem, caso levemos em conta a visão de mundo tipicamente xenófoba da Atenas clássica. Há ali um certo ar de festividade misturado a uma atmosfera de confusão que aponta para a falta de um princípio de governança adequado, antecipando, por fim, muitos dos temas pelos quais o diálogo é conhecido.

\footnotetext{
3 "The Republic is no less a mimetic poem than are the Iliad and the Odyssey". Esta e demais traduções são de autoria dos articulistas, salvo quando indicadas.

${ }^{4}$ As referências à obra platônica partem da tradução de Carlos Alberto Nunes (PLATÃO, 2000).

${ }^{5}$ Stanley Rosen (2005, p. 282-283) relaciona a cena da descida do filósofo esclarecido "in the just city into the domain of shadows", descrita no célebre Mito da Caverna em 520c. Tanto no mito em questão quanto na cena de abertura da República I, há abertura para uma interpretação política dos espaços descritos; o verbo utilizado em ambos os casos para designar a descida é o mesmo, $\varkappa \alpha \tau \dot{\alpha} \beta \varepsilon v$.
} 
Consideremos a cena que se segue: Sócrates, acompanhado de amigos, volta do festival e é abordado por Polemarco, que pede para que fique por ali (327a) ${ }^{6}$. Polemarco, por sua vez, está acompanhado de demais personagens: Adeimanto, Nicerato, entre outros. Todos eles coagem Sócrates a segui-los. Este resiste, a princípio, questionando (ironicamente) se não há nenhuma forma de persuadi-los a deixarem-no ir (327c). Dizemos ironicamente, pois Sócrates parece encenar uma característica pela qual é conhecido nos diálogos platônicos iniciais: ele é aquele capaz, mediante o domínio da dialética, de persuadir seus interlocutores a agirem baseados em pressupostos falsos e por força da própria tolice. Esta não é a única referência à fama de Sócrates no diálogo; ver também trecho 337a, onde Trasímaco diz: "ó Héracles! Eis mais uma amostra da conhecida ironia de Sócrates”. É como se Platão retratasse Sócrates como uma personagem que, tal qual em um romance, possui uma certa reputação e história pessoal a qual a narrativa vai revelando aos leitores, gradativamente. $\mathrm{O}$ trecho, em outras palavras, serve à marcação de características constituintes de uma personagem das quais os leitores deverão estar conscientes dali para frente no decorrer da narrativa. Esse é um dos muitos aspectos que nos permite aliar a construção textual dos diálogos platônicos a obras de ficção literária bastante suigeneris.

O artifício socrático, porém, não surte efeito; os interlocutores em questão, diferentemente daqueles de diálogos anteriores à República, não estão dispostos a ouvi-lo: "de que modo [...] conseguirás convencer quem não quer ouvir?" (327c), um deles diz. O trecho cria a crise inicial, "uma sequência de frustrações" nas palavras de Benardete (1989, p. 11), que reforçam a imagem do ambiente do Pireu como um ambiente insubordinado à governança da razão. Sócrates não consegue chegar a sua casa em Atenas, por exemplo; posteriormente, é forçado a acompanhar os companheiros à casa do pai de Polemarco e, embora seja agraciado com um banquete, não tem tempo de se alimentar, visto que os convivas se apressam para ver uma corrida realizada nas proximidades (à qual não conseguirão assistir por conta de uma nova complicação (ver 354a-354c). O contexto é um do mais completo desacordo. As intenções nutridas, a princípio, parecem não se concretizar naquele ambiente.

Antes de passarmos à cena do diálogo socrático com Céfalo, há de se perguntar se o contexto histórico nos traz camadas de significado relevantes para a compreensão do texto. Alguns dados do trecho inicial supracitado - como o fato de Sócrates estar indo para o primeiro festival de Bendis - o situa em meados de junho de 429 AEC, segundo o estudo de Planeaux (2000, p. 182-3) ${ }^{8}$. Esta época será descrita, posteriormente, como "uma 'idade de ouro', antes de os desdobramentos sociais, culturais e tecnológicos aos quais Atenas fora submetida terem ocorrido" (PURSHOUSE, 2006, p. 36) ${ }^{9}$. Fica a sugestão de que desdobramentos posteriores da história destruíram a simplicidade (ou idealismos inocentes) daquela geração. Sabe-se que o grande marco da política interna de Atenas, posterior a meados de 429 AEC, foi a supressão de sua estrutura democrática e sua

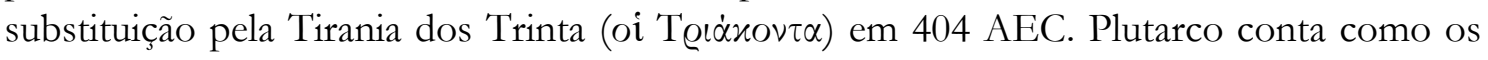
espartanos invadiram Atenas e estabeleceram uma espécie de governo ditatorial gerido por

\footnotetext{
${ }^{6} \mathrm{O}$ narrador introduz Polemarco como se estivesse presente quando Polemarco o avista (ver 327b 2-4), como ressalta Seth Benardete (1989, p. 9); sua visão de personagem-narrador muitas vezes assume curiosos tons de onisciência, o que, mais uma vez, reforça o caráter literário do diálogo.

7 "[...] a series of frustrations".

${ }^{8}$ Não há consenso na fortuna crítica quanto à data exata, embora as propostas de historiadores situem o festival inaugural de Bendis entre 413 e 430 AEC (ver complementos à pesquisa de Planeaux em JANOUCHOVÁ, 2013, p. 97, nota 4).

9 "[...] a 'golden age', before the social, cultural and technological developments Athens had undergone [took place]".
} 
trinta regentes; vendo que a dissidência pró-democracia havia se concentrado justamente no Pireu, estabeleceram mais dez tiranos naquele lugar, a fim de conter rebeliões (PLUTARCO, 1952, p. 359-360). Contudo, o evento da Tirania dos Trinta em si não parece ter implicações diretas no desdobrar da narrativa. Antes, o fato de o Pireu de meados de 429 AEC ser um cenário prévio à supressão histórica da democracia ateniense parece ser relevante, além de elucidativo dos diálogos travados por Sócrates. Foi a partir desse cenário de crise que a República, como sabemos, consagrou-se como texto privilegiado da filosofia por discutir pautas relevantes para nossas sociedades até os dias de hoje (PURSHOUSE, 2006, p. 139 et seq). Algumas delas são: vale a pena lutar pela democracia? Se não, qual sistema de governo é mais adequado para manutenção da pólis e de uma boa vida (dois temas que, aliás, estão intimamente interligados para Sócrates e são expressos, mutatis mutandis, em 329c-331c)? Quais são os elementos (ou partes funcionais) constitutivos de uma pólis, e como harmonizá-los de forma a fazê-la funcionar com eficácia (368a-376c)? No que consiste a justiça (331e-352d)? No que consistem as virtudes da alma dos cidadãos que habitarão a pólis ideal (434d-445e) ${ }^{10}$

Já na construção de seu cenário, portanto, o texto antecipa discussões desenvolvidas nos diálogos propriamente ditos entre Sócrates e seus interlocutores. As próprias personagens, cujo caráter se deixa conhecer no decorrer dos diálogos, se revertem em grandes representantes de forças sociais ou interesses coletivos que marcaram a trajetória histórica de Atenas: Trasímaco, por exemplo, aparece perante Sócrates como um jovem sofista sanguíneo e arrogante. É ele que acusa este de ser ignorante por não saber que a justiça é simplesmente "o interesse do mais forte", algo danoso àqueles que estão subordinados ao líder (344c). Todavia, Trasímaco não só representa um indivíduo de vontade implacável, que se vale de força para atingir seus objetivos; ele foi uma figura histórica, apoiador da oligarquia ateniense de 411 AEC e peça fundamental durante a conquista espartana de 404 AEC. Com a subida da Tirania dos Trinta, os poucos oligarcas atenienses que deram suporte aos invasores assassinariam Nicerato e Polemarco, os mesmos que discutiam com o futuro traidor Trasímaco.

De acordo com a pesquisa de Krentz (1982, p. 79-82), Polemarco e Lísias possuíam uma manufatura de escudos que foi logo ocupada pelos Trinta Tiranos. No processo de ocupação, ambos foram assassinados ${ }^{11}$. Plutarco (1952, p. 359) estima que três mil dissidentes atenienses aprisionados por Lisandro foram assassinados na passagem da Guerra do Peloponeso e a Tirania dos Trinta; Platão representa o grupo em questão, portanto, tendo se baseado em uma cuidadosa seleção de personagens.

Aqui, portanto, não temos apenas Sócrates se entretendo com uma ampla gama de personalidades, representadas por meros rótulos (Glauco, Trasímaco, Céfalo etc). Antes, é possível observar uma manipulação de figuras histórias reais que, durante um período conturbado da história ateniense, foram mortas por suas divergências a respeito do que

\footnotetext{
${ }^{10}$ Nota para futuros desenvolvimentos da problemática, que fogem das convenções dos estudos clássicos, mas que insistimos em pontuar aqui, por força das circunstâncias: com o surgimento do trumpismo internacional (que deu vazão à escolha democrática, em grandes nações, por representantes antidemocráticos), todas essas questões voltam à ordem do dia com grande intensidade. Destaque para os livros recentes How democracies die de Steven Levitsky e Daniel Ziblatt (2018) e How democracy ends de David Runciman (2018). Curiosamente todos eles, talvez por se tratarem de obras de popularização de estudos de ciência política para leigos, esquecem de fazer menção à discussão inicial da obra que inaugurou a ciência política no Ocidente, a Politeia de Platão. Runciman menciona Platão uma vez, de modo fugidio, mas só para descartá-lo como um antidemocrata incorrigível.

${ }^{11}$ Relatos do evento são mencionados também na Hellenica 2.3.39 de Xenofonte; em Diodorus Siculus 14.5.5; nos Discursos de Lysias 12.19, 18.6, 19.47, 30.12; além da Moralia de Plutarco 998b.
} 
seria uma vida política digna. Há, no desenvolvimento do texto, uma correlação íntima entre personagem (simultaneamente histórica e ficcionalmente constituída) e argumentação filosófica (GEIGER, 2009, p. 364). Tal correlação dá aos textos platônicos o caráter "dramático" comumente atribuído pela crítica: o diálogo, como forma histórica, por si só introduz a oposição entre duas personagens bem delineadas como elemento-guia da narrativa. Essa é uma oposição que, seguindo a lógica da dialética platônica, supostamente deve chegar a uma conclusão, à vitória de uma das partes (ibidem, p. 366-372).

Nesse sentido, o fato de o diálogo propriamente dito da República se iniciar com o embate entre Sócrates e Céfalo é bastante significativo. Ele se situa no início do texto de forma a definir o tom de sua continuação. Em 328d, o velho pai de Polemarco recebe Sócrates tal qual a um convidado ilustre: "É muito raro, Sócrates, baixares ao Pireu para visitar-nos. Mas, precisavas fazê-lo. Se eu ainda tivesse vigor suficiente para ir à cidade sem cansar-me, poupar-te-ia o trabalho de vires até aqui; nós mesmos te visitaríamos" (328c328d). O mesmo Céfalo se mostra uma figura mais adequada à região intersticial representada pelo espaço do Pireu; temos a impressão que a personagem aceita a idade avançada como desculpa para não participar da vida social ateniense. Ele é uma versão antiga do isento político. Em um nível estritamente pessoal, Céfalo não se subordina aos ditames da razão e se entrega a prazeres próprios da vida de um idoso de condição abastada. Ao reconhecer outro homem de sua faixa etária, ademais, ele sugere que haja uma separação radical entre as ocupações dos jovens (voltados aos "prazeres do corpo; 328d) e as ocupações da velhice ("a necessidade de conversar e a alegria que esses colóquios proporcionam"; idem). O pretenso exercício de empatia parece irritar Sócrates, tendo em vista a curiosa inversão que faz na conversa; em uma ocasião única no diálogo, Sócrates se mostra algo agressivo perante seu interlocutor: "Teria muito prazer em ouvir-te discorrer a esse respeito, uma vez que já atingiste a idade que os poetas denominam 'soleira da velhice' é a fase mais difícil da vida, ou como a consideras?” (328e). É como se Sócrates exigisse maior rigor intelectual do homem lembrando-o de sua morte próxima.

A pergunta dá ensejo, em seguida, a outra de maior profundidade filosófica: o que constitui uma boa vida? Céfalo discorre sobre as vantagens da idade avançada com base nos limites impostos pelas circunstâncias: os desejos sexuais arrefecem e "quando alguém imagina estar próximo de morrer, fica tomado de temor e de inquietação a respeito de coisas que antes o deixavam indiferente" (330d). Em outras palavras, o medo da morte torna o indivíduo mais propenso ao ascetismo, à obediência das regras sociais, do vó $\mu o s$. Sócrates satiriza a ideia proposta questionando se um homem pobre e faminto teria os mesmos privilégios. Aqui, torna-se evidente que "a ligação entre a moderação de Céfalo e a justiça de Céfalo é o dinheiro" (ROSEN, 2005, p. 14) ${ }^{12}$; esta é a fraqueza principal de seu argumento. De fato, a riqueza "enseja a possibilidade de deixar a vida sem receio de haver mentido [...] e de não ter ficado devendo sacrifício a nenhum dos deuses nem dinheiro a ninguém" (331b), Céfalo reitera, criando um caso específico para justificar seu posicionamento ante a questão. Sócrates, por sua vez, retruca:

falaste admiravelmente, Céfalo. Porém, com relação a essa mesma justiça, bastará defini-la como o fizeste, e dizer que consiste apenas em falar verdade e restituir o que recebemos de outrem, ou é fato que em qualquer caso podemos proceder com justiça ou injustamente, conforme as circunstâncias? (331c)

12 “[...] the link between Cephalus' moderation and Cephalus' justice is money". 
Com essa correção, vê-se que Sócrates e todos seus interlocutores futuros, independentemente de suas falhas e sofismas, buscarão um princípio de justiça universal, pautado na razão. Céfalo parece representar tudo aquilo a que o diálogo platônico deve se opor, o senso comum e o enviesamento determinado por circunstâncias particulares (ROSEN, 2005, p. 15). Nesse sentido, o discurso de Céfalo se insere no texto como um contraexemplo, uma amostra de como o diálogo não deve se desenvolver.

Embora um interlocutor posterior como Trasímaco seja retratado como uma personalidade rude, agressiva (PURSHOUSE, 2006, p. 21-22), seu não-comodismo o torna um interlocutor apto para mobilizar a discussão mediada pela dialética platônico-socrática. Ele tem espaço no diálogo e, portanto, figura como personagem apta dentro do registro filosófico. Céfalo, por sua vez, não volta a aparecer em cenas subsequentes.

Platão, portanto, construiu cenários e quadros de personagens bastante complexos, que antecipam muito das discussões desenvolvidas em seu texto; eles como que guiam a leitura, dando um enfoque a questões centrais do diálogo que, embora às vezes pareçam se perder em longos excursos por parte de interlocutores secundários (Céfalo, Trasímaco e Glauco, por exemplo), sempre voltam à pauta por força da mediação socrática. $\mathrm{O}$ uso do cenário, esse dispositivo próprio da poesia, serve para a manutenção de uma metodologia dialética rígida, não à mera persuasão e a devaneios da imaginação, condenados por sua personagem Sócrates a partir de 366b. Sua construção poética, portanto, é um contraexemplo das "fábulas mentirosas" que, mesmo que fossem reais, "não deveriam ser contad[a]s com tanta leviandade a jovens de pensamento imaturo" (377d-378a), como se lê no famoso trecho da República II em que se condena a tradição poética grega desde Hesíodo e Homero. Isso nos leva a repensar a simplificação tão comum de compêndios de filosofia de que o Sócrates platônico era um racionalista dogmático, avesso a qualquer forma de belas artes.

\section{Referências}

BENARDETE, S. Socrates' Second Sailing. On Plato's Republic. Chicago; London: The University of Chicago Press, 1989.

COOPER, J. M. (Org.). The Complete Works of Plato. Indianapolis: Hackett Publishing Co., 1997.

GEIGER, R. Literarische Aspekte der Schriften Platons. In: HORN, C.; MÜLLER, J.; SÖDER, J. (Org.). Platon Handbuch: Leben - Werke - Wirkung. Stuttgart: J. B. Metzler Verlag, 2009, p. 363-386.

JANOUCHOVÁ, P. The cult of Bendis in Athens and Thrace. Graeco-Latina Brunensia, v. 18, n. 1, p. 95-106, 2013. Disponível em: http://hdl.handle.net/11222.digilib/127199. Acesso em: 07 fev. 2020.

KRENTZ, P. The Thirty at Athens. Ithaca; London: Cornell University Press, 1982.

LEVISTKY, S.; ZIBLATT, D. How democracies die. New York: Broadway Books, 2018. 
PLANEAUX, Christopher. The date of Bendis' entry into Attica. The Classical Journal, v. 96, n. 2, p. 165-192, 2000.

PLATÃO. A República. Ou: sobre a justiça. Gênero Político. Tradução: Carlos Alberto Nunes. Belém: UFPA, 2000.

PLUTARCO. L. In: The lives of the noble Grecians and Romans. Chicago; London; Toronto: Encyclopaedia Britannica, 1951, p. 354-367.

PURSHOUSE, L. Plato's Republic. London: Continuum, 2006.

ROSEN, S. Plato’s Republic: a study. London; New Haven: Yale University Press, 2005.

RUNCIMAN, D. How democracy ends. New York: Basic Books Publishing, 2018. 